\title{
CFD modelling of two-phase liquid-liquid flow in a SMX static mixer
}

\author{
Paulina Pianko-Oprych ${ }^{1}$, Zdzisław Jaworski ${ }^{2}$ \\ West Pomeranian University of Technology,, Institute of Chemical Engineering and Environmental Protection Processes, \\ al. Piastow 42, 71-065 Szczecin, Poland \\ ${ }^{1}$ Corresponding author: e-mail: Paulina.Pianko@zut.edu.pl \\ ${ }^{2}$ Corresponding author: e-mail: Zdzislaw.Jaworski@zut.edu.pl
}

\begin{abstract}
The paper provides an overview of the application of Computational Fluid Dynamics tools for predicting transport processes in two-phase flow in a SMX static mixer. The overview is achieved by taking a brief look at factors: mesh generation, development of sub-models, post-processing including validation and quantitative verification of CFD results with experimental data. Two types of numerical approach were used in the simulations: the Reynolds averaged Navier-Stokes in the steady-state mode with the standard $k-\varepsilon$ turbulence model and Large Eddy Simulations in the unsteady mode. Both CFD techniques were applied to calculate flow velocities, pressure drop and homogenisation level in a SMX static mixer of the liquid-liquid mixture. The steady state drop size distribution was obtained by implementation procedure containing the population balance equation, where transport equations for the moments of the drop size distribution are solved and the closure problem is overcome by using the Quadrature Method of Moments.
\end{abstract}

Keywords: CFD, LES, QMOM, two-phase flow, liquid-liquid dispersion, SMX static mixer.

\section{INTRODUCTION}

Fluid flow through a SMX static mixer and liquid-liquid dispersion analysis are common in chemical engineering. The conventional approaches of conducting experiments on static mixers have their own disadvantages, which fully or partially prevent full characterization of the mixing efficiency of the static mixer. The LDA and PIV techniques for velocity measurements can handle only very low liquid volume fraction, because their accuracy is dependent on the transparency to laser light relative to the dispersed phase concentration. The dispersed phase volume fraction, when using matched refractive indices in combination with advanced image analysis could be up to 0.7 wt. $\%$ or 1.5 wt. $\%$ as shown by Bottone ${ }^{1}$ and Virdung and Rasmuson ${ }^{2}$, respectively, which still is not a sufficiently high value in most practical systems. Therefore, the application of Computational Fluid Dynamics (CFD) tools for predicting transport processes in static mixers seems fully justified. CFD calculations can be done even at high concentrations of the dispersed phase, for nonNewtonian liquids and three phase systems. This method of analysis is almost certainly less expensive than experiment and represents a cost-effective route for design optimization.

Only a few papers describing dispersion of liquid-liquid systems in a SMX static mixer have been published so far. They were mainly of experimental nature. The authors focused on single drop breakup measurements in a very viscous continuous phase laminar flow ${ }^{3-6}$, at intermediate Reynolds number ${ }^{7}$ and only one paper is related to turbulent flow ${ }^{8}$. Results obtained by Theron et al. ${ }^{8}$ are in agreement with the observations of Streiff et al. ${ }^{9}$, who proposed a correlation (1) for the prediction of droplet size in turbulent flow in the SMX static mixer:

$\mathrm{d}\left(\varphi_{\mathrm{d}}\right)=\mathrm{C}_{\mathrm{n}}\left(1+\mathrm{k} \varphi_{\mathrm{d}}\right)\left(\frac{(1+\mathrm{B} \cdot \mathrm{Vi}) \mathrm{We} \mathrm{c}_{\mathrm{c}}}{2}\right)^{0.6}\left(\frac{\sigma}{\rho_{\mathrm{c}}}\right)^{0.6}\left(\frac{\rho_{\mathrm{c}}}{\rho_{\mathrm{d}}}\right)^{0.2} \varepsilon^{-0.4}$
In addition, concentration distributions were determined as an essential measure of homogeneity level. A widely used measure for presenting the uniformity of concentration at a cross-section of static mixers is the coefficient of variation $(\mathrm{COV})$. The $\mathrm{COV}$ is defined as the standard deviation of concentration over the mean concentration for a given set of $\mathrm{N}$ data points (eqn. (2)):

$\operatorname{COV}=\frac{\sqrt{\frac{1}{N-1} \sum_{i=1}^{N}\left(X_{i}-\bar{X}\right)^{2}}}{\bar{X}}$

where $\bar{X}$ is the mean concentration. The data used to calculate the $\mathrm{COV}$ are taken at a specified number of grid nodes at the cross section planes. Thus $\mathrm{COV}=0$ for a complete distributive mixing, while $\operatorname{COV}=[\bar{X}(1-\bar{X})]^{1 / 2}$ represents total segregation. An alternative functional form used to fit COV data is defined in equation (3):

$C O V=a \cdot \exp \left(-\frac{b \cdot L_{m}}{D}\right)$

where $\mathrm{a}$ and $\mathrm{b}$ are adjustable constants. The parameter $\mathrm{b}$ represents the rate of decrease in $\mathrm{COV}$ per unit of mixer length. Pahl and Muschelknautz ${ }^{10}$, Allocca ${ }^{11}$, GroszRoll ${ }^{12}$, Cybulski and Werner ${ }^{13}$ estimated parameters $a$ and $b$ from experimental results for the SMX static mixer with $\mu_{c} / \mu_{d}>1$ and laminar flow. The results for turbulent flow are given by Grosz-Roll ${ }^{12}$ for the Sulzer SMV only.

The values of the exponents in equation (3) were $a \approx 15$, $b \approx-0.505$ for the SMX static mixer in laminar flow ${ }^{12-13}$ and $a \approx 1.7, b \approx-0.755$ for the SMV static mixer in turbulent flow ${ }^{12}$.

Numerical studies on the SMX static mixer so far have been mostly focused on the fluid flow, residence time distribution, pressure drop, concentration distributions and heat transfer for both Newtonian and non-Newtonian fluids $^{14-16}$. The residence time calculations determined by particle tracking resulted in Peclet number of 4.2 per SMX element being in good agreement with experimental values ${ }^{17}$. Several groups have tried to improve the SMX static mixer performance by modifying its geometry ${ }^{16-19}$. 
Hirschberg et al. ${ }^{16}$ modified the SMX geometry by reducing the number of bars to 6 and by reducing the number of gaps between the bars. Both CFD simulations as well as the laser induced fluorescence (LIF) experiments show that the pressure drop along the mixer was reduced to less than $50 \%$ while the mixing quality after a given number of elements remains nearly equivalent with the original $\mathrm{SMX}^{\mathbf{1 6}}$. The drop break-up process in the flow of liquidliquid dispersions in the SMX static mixer at low and intermediate Reynolds number has been investigated by Das et al. ${ }^{7}$. Das et al. ${ }^{7}$ proposed two new theoretical models for the drop break-up using the boundary-layer shear force concept to predicting the drop beak-up at low and intermediate Reynolds number and also for the effect of inertia on the drop break-up assuming that the flow through the static mixer elements is analogous to the flow through porous media. Good agreement between simulations and experiments showed that finite element simulation can properly represent the very complex velocity field generated by the SMX static mixer and the predicted drop sizes are in reasonable agreement with experimental results (the root-mean square relative error was around $5 \%)^{7}$. Therefore, it can be concluded that the prediction of velocity field, pressure drop, concentration and drop size distribution in the SMX static mixer for low and intermediate Reynolds number has been accurately analyzed using standard CFD solvers and a fine grid resolution ${ }^{\mathbf{2 0}-\mathbf{2 1}}$. The exponential growth of computer power allows for simulations with highly resolved grids not only for laminar flows within the SMX static mixer, but it is also possible to handle simulations in turbulent conditions, which are much more difficult to carry out.

This study is undertaken to investigate the capability of simulation methods to estimate the behaviour of liquidliquid dispersion in the SMX static mixer under turbulent conditions. As a first part of the study, the flows of three different levels of density ratio of two immiscible liquids through the SMX static mixer are investigated using the RANS and LES approaches and compared with experiments ${ }^{10,11,14,22}$ both for miscible and immiscible liquids. The investigation covers the effects of density ratio between the phases and the impact of the centrifugal force on the phase concentration distribution. In a second part of the study, drop breakage in a liquid-liquid system is analysed using the Quadrature Method of Moments. Those results are also validated by experimental data ${ }^{22}$.

\section{THEORETICAL}

As already mentioned, two approaches have been employed here: the Reynolds averaged Navier-Stokes (RANS) and Large Eddy Simulation (LES) methods. The twophase flows in the RANS approach were modelled using a two-fluid model called the Mixture model available in the commercial CFD code Fluent 6.3.26. The continuity equations (4) and (5) of the mixture (subscript $\mathrm{m}$ ) and of the dispersed phase (subscript d) were solved for the steady-state conditions:

$$
\begin{aligned}
& \frac{\partial}{\partial x_{i}}\left(\rho_{m} \overline{v_{m}, i}\right)=0 \\
& \frac{\partial}{\partial x_{i}}\left(X_{d} \rho_{d} \bar{V}_{m, i}\right)=-\frac{\partial}{\partial x_{i}}\left(X_{d} \rho_{d} \bar{V}_{\text {Drd }, i}\right)
\end{aligned}
$$

together with the momentum RANS equations (6):

$\frac{\partial}{\partial x_{j}}\left(\rho_{m} \bar{v}_{m, i} \bar{v}_{m, j}\right)=-\frac{\partial \bar{p}}{\partial x_{i}}+\frac{\partial}{\partial x_{j}}\left(\mu_{m} \frac{\partial \bar{v}_{m, i}}{\partial x_{j}}-\overline{\rho_{m} v_{m, i}^{\prime} v_{m, j}^{\prime}}\right)+F_{i}$

(6)

where the terms $\overline{\rho_{\mathrm{m}} \mathrm{v}_{\mathrm{m}, \mathrm{i}}^{\prime} \mathrm{v}_{\mathrm{m}, \mathrm{j}}^{\prime}}$ are the Reynolds turbulent stresses expressed in equation (7):

$-\overline{\rho_{\mathrm{m}} \mathrm{v}_{\mathrm{m}, \mathrm{i}}^{\prime} \mathrm{v}_{\mathrm{m}, \mathrm{j}}^{\prime}}=\mu_{\mathrm{T}}\left(\frac{\partial \overline{\mathrm{v}_{\mathrm{m}, \mathrm{i}}}}{\partial \mathrm{x}_{\mathrm{j}}}+\frac{\partial \overline{\mathrm{v}_{\mathrm{m}, \mathrm{j}}}}{\partial \mathrm{x}_{\mathrm{i}}}\right)-\frac{2}{3} \rho_{\mathrm{m}} \mathrm{k} \delta_{\mathrm{ij}}$

The Reynolds stresses were modelled using the twoequations standard $k-\varepsilon$ model (equations 8 and 9), where eddies are modelled in the entire range of scales ${ }^{\mathbf{2 3}}$ :

$\frac{\partial}{\partial x_{i}}\left(\rho_{m} \overline{v_{m, i}} k\right)=\frac{\partial}{\partial x_{i}}\left(\left(\mu_{m}+\frac{\mu_{T}}{P_{k}}\right) \frac{\partial k}{\partial x_{i}}\right)-\rho_{m} \varepsilon-\rho_{m} \overline{v_{m, i}^{\prime} v_{m, j}^{\prime}} \frac{\partial \overline{v_{m, i}}}{\partial x_{i}}$

$\frac{\partial}{\partial x_{i}}\left(\rho_{m} \overline{v_{m, i}} \varepsilon\right)=\frac{\partial}{\partial x_{i}}\left(\left(\mu_{m}+\frac{\mu_{T}}{P_{\varepsilon}}\right) \frac{\partial \varepsilon}{\partial x_{i}}\right)+C_{1} \frac{\varepsilon}{k}\left(-\rho_{m} \overline{v_{m, i}^{\prime} v_{m, j}^{\prime}} \frac{\partial \overline{v_{m, i}}}{\partial x_{i}}\right)-\rho_{m} C_{2} \frac{\varepsilon^{2}}{k}$

where $k$ is the turbulent kinetic energy and $\varepsilon$ its dissipation rate. The turbulent eddy viscosity is specified as follows (10):

$\mu_{\mathrm{T}}=\rho_{\mathrm{m}} \mathrm{C}_{\mu} \frac{\mathrm{k}^{2}}{\varepsilon}$

Equations (9) and (10) contain adjustable constants: $C_{\mu}=0.09 ; C_{1}=1.44 ; C_{2}=1.92 ; P_{k}=1.00 ; P_{\varepsilon}=1.314$. The drift velocity of the dispersed phase, $v_{D r d, i}$, is computed from one of the available choices of algebraic expressions, which account for the hydraulic drag of the dispersed phase and local acceleration of the mixture.

In the LES approach the governing equations are obtained by spatially filtering the Navier-Stokes equations: $\frac{\partial}{\partial t}\left(\rho_{m} \widetilde{v}_{m, i}\right)+\frac{\partial}{\partial x_{j}}\left(\rho_{m} \widetilde{v}_{m, i} \widetilde{v}_{m, j}\right)=-\frac{\partial \widetilde{p}}{\partial x_{i}}+\frac{\partial}{\partial x_{j}}\left(\mu_{m} \frac{\partial \widetilde{v}_{m, i}}{\partial x_{j}}\right)-\frac{\partial \tau_{i j}}{\partial x_{j}}$

The large eddies are resolved directly, while the small eddies are modelled using the sub-grid scale dynamic Smagorinsky-Lilly model. $\tau_{i j}$ denotes sub-grid scale stress defined by eqn. (12):

$\tau_{\mathrm{ij}}=\mu_{\mathrm{T}}\left(\frac{\partial \widetilde{\mathrm{v}}_{\mathrm{m}, \mathrm{i}}}{\partial \mathrm{x}_{\mathrm{j}}}+\frac{\partial \widetilde{\mathrm{v}}_{\mathrm{m}, \mathrm{j}}}{\partial \mathrm{x}_{\mathrm{i}}}\right)$

The eddy viscosity in the Smagorinsky-Lilly model is modelled by equation (13):

$\mu_{\mathrm{T}}=\rho_{\mathrm{m}} \mathrm{L}_{\mathrm{s}}^{2}|\overline{\mathrm{S}}|$

with $L_{s}$ being the mixing length for sub-grid scales. In the Fluent software $L_{s}$ is computed using equation (14):

$\mathrm{L}_{\mathrm{s}}=\min \left(\mathrm{Kd}, \mathrm{C}_{\mathrm{s}} \mathrm{V}^{1 / 3}\right)$

$K$ is the Von Karman constant, $K=0.42, d$ is the distance to the closest wall, $V$ is the volume of the computational cell. $C_{s}$ was set to $0.1^{24}$. The filtered rate of strain, $|\bar{S}|$, is obtained from:

$|\bar{S}|=\sqrt{2 \overline{S_{i j}} \overline{S_{i j}}}$ 
where $\overline{S_{i j}}$ is the rate of strain tensor components for the resolved scale.

According to the literature guidelines ${ }^{25}$ the second order approximation schemes should be used in the numerical LES modelling. In addition, the representative cell size, $h$, should be smaller than the size of the energy conveying eddies ${ }^{25}$. It means the reciprocal of the filter wavenumber, $\kappa_{f}$, should be smaller than the lateral Taylor microscale of turbulence, $\lambda_{g}$, (16):

$\left(\kappa_{\mathrm{f}}\right)^{-1}<\lambda_{\mathrm{g}}$

The local value of the Taylor microscale was estimated from the values obtained by the $k$ - $\varepsilon$ turbulence model used in the RANS simulations. Assuming the local isotropy of turbulence, the microscale is given by equation (17):

$\lambda_{\mathrm{g}}=\sqrt{\frac{10 \mu_{\mathrm{m}} \mathrm{k}}{\rho_{\mathrm{m}} \varepsilon}}$

The local size of the applied grid of $854 \mathrm{k}$ cells was compared with the local Taylor microscale of turbulence, $\lambda_{g}$, and it was found that the average grid size conforms with the criterion expressed in equation (16). For the considered case, the average values of the turbulent kinetic energy, $k$, and its rate of dissipation, $\varepsilon$, obtained from the RANS simulations were approximately equal to 0.018 $\left[\mathrm{m}^{2} / \mathrm{s}^{2}\right]$ and $2.98\left[\mathrm{~m}^{2} / \mathrm{s}^{3}\right]$ for $R e=10000$, respectively. The average values of the Taylor microscale, $\lambda_{g}$, estimated from equation (17) was 0.00023 [m]. With the grid of $854 \mathrm{k}$ cells the average cell size, $h$, was approximately equal to $4.5 \cdot 10^{-5}[\mathrm{~m}]$, which does not exceed the value of the Taylor microscale.

The LES was started from RANS solutions in transient mode and with the sub-grid scale turbulence model of Smagorinsky-Lilly and it was also carried out for the three cases described in Experimental. The time step of 0.001 [s] and 30 internal iterations for each time step were assumed. The total number of 500 time steps was executed, which resulted in the total LES time of 0.5 [s]. The default second-order discretization schemes and underrelaxation factors of the CFD code were applied in the simulations. The plateau level of residuals achieved in LES was slightly above $10^{-4}$.

The next step in the numerical analysis comprised computation of the drop breakage within the SMX static mixer given by the population balance equation. The population balance equation was used in a form of the transport equation for the $\mathrm{k}$-th moment for the particle size distribution $(\mathrm{PSD})^{26}$ :

$\left\langle\mathrm{u}_{\mathrm{i}}\right\rangle \frac{\partial \mathrm{m}_{\mathrm{k}}(\mathrm{x}, \mathrm{t})}{\partial \mathrm{x}_{\mathrm{i}}}-\sum_{\mathrm{i}} \frac{\partial}{\partial \mathrm{x}_{\mathrm{i}}}\left[\Gamma_{\mathrm{t}} \frac{\partial \mathrm{m}_{\mathrm{k}}(\mathrm{x}, \mathrm{t})}{\partial \mathrm{x}_{\mathrm{i}}}\right]=\sum_{\mathrm{i}} \mathrm{a}_{\mathrm{i}} \overline{\mathrm{b}_{\mathrm{i}}^{(\mathrm{k})}} \mathrm{w}_{\mathrm{i}}-\sum_{\mathrm{i}} \mathrm{a}_{\mathrm{i}} \mathrm{w}_{\mathrm{i}} \mathrm{L}_{\mathrm{i}}^{(\mathrm{k})}$

where the moment number $(\mathrm{k}=0,1,2, \ldots \mathrm{K})$. Population balance was analyzed for the RANS method only. Since that approach uses the Reynolds average variables, the inertial term in Eq. (18) for the moments of the drop size distribution, $\partial \mathrm{m}_{\mathrm{k}} / \partial_{\mathrm{t}}$, was not considered for the average steady state flow conditions. Solution of the set of $(K+1)$ moment equations is achieved with the help of a quadrature approximation proposed by $\mathrm{McGraw}^{27}$. That procedure is applied together with the Product-Difference algorithm ${ }^{\mathbf{2 8}}$, which allows to estimate the weights, $\mathrm{w}_{\mathrm{i}}$, and abscissas, $\mathrm{L}_{\mathrm{i}}$, used in the approximation. The joint use of the moment version and the quadrature approximation is called the Quadrature Method of Moments (QMOM), which was described in detail by Marchisio et al. ${ }^{26}$. In computations the exponential model for the drop breakage frequency, $a_{i}$, was assumed:

$\mathrm{a}_{\mathrm{i}}=3.8 \cdot 10^{-3} \cdot \varepsilon^{3 / 4} \cdot\left(\frac{\mu_{\mathrm{d}}}{\mu_{\mathrm{c}}}\right)^{-5 / 4} \cdot \mathrm{L}_{\mathrm{i}}$

Using the assumption that the breakage process results only in the division into two equal volume daughter drops, the daughter distribution function, $b\left(L \backslash L_{i}\right)=2$, which leads to eqn. (20) for the k-th moment of the distribution function for the daughter drops, $\overline{b_{i}^{(k)}}$ :

$\overline{b_{i}^{(k)}}=\int_{0}^{\infty} L^{k} b\left(L \backslash L_{i}\right) d L=2^{(3-k)} L_{i}^{k}$

In the opposite case no breakage occurs and then $b\left(L \backslash L_{i}\right)=0$.

Reconstruction of the drop size distribution was done with the help of the drop density distribution function described by eqn. (21) and proposed by Randolph and Larson $^{29}$ :

$\mathrm{f}_{\mathrm{N}}(\mathrm{L})=\left(\frac{1}{\sqrt{2 \pi} \cdot \log (\sigma)}\right) \cdot \exp \left[-\left(\frac{\log \left(\frac{\mathrm{L}}{\overline{\mathrm{L}}}\right)}{\sqrt{2} \cdot \log (\sigma)}\right)^{2}\right]$

or as a cumulative drop distribution function (eqn. (22)):

$\mathrm{F}_{\mathrm{N}}(\mathrm{L})=0.5 \cdot\left(1+\operatorname{erf}\left(\frac{\log \left(\frac{\mathrm{L}}{\overline{\mathrm{L}}}\right)}{\sqrt{2} \cdot \log (\sigma)}\right)\right)$

The mean drop size, $\overline{\mathrm{L}}$, and the drop size standard deviation, $\sigma$, are defined in Nomenclature and can be calculated from the first three moments, $\mathrm{m}_{0}$ to $\mathrm{m}_{2}$, using the relationships given in Nomenclature.

\section{EXPERIMENTAL}

A static mixer with six SMX inserts was used in this study. A single SMX insert consists of a set of strips (blades) located alternatively at the angle of $45^{\circ}$ or $-45^{\circ}$ to the mixer axis and cut to fit the mixer tube (Fig.1a). The inserts are axially rotated by the angle of $90^{\circ}$ relative to their neighbours (Fig.1b). The height of the insert was 27.5 [mm], its diameter 25.0 [mm], the width of a single strip $3.1[\mathrm{~mm}]$ and its thickness 1.0 [mm]. The total length of the modelled mixer tube was 357.5 [mm] with the inlet section of $55.0[\mathrm{~mm}]$ and the outlet section of $137.5[\mathrm{~mm}]$.

In the first stage of the numerical modelling, computations of turbulent momentum transfer based on either the standard RANS approach or the LES approach were carried out. At that stage the drop diameter was assumed constant. The Sauter mean diameter used for the SMX mixer was constant $1.005[\mathrm{~mm}]$ for $\mathrm{Re}=10000^{30}$ both in the RANS and LES modelling, while when the drop population balance equations in the QMOM version were solved, the following estimated initial values of the six moments were used: $\mathrm{m}_{0}=1.88 \cdot 10^{9}\left[1 / \mathrm{m}^{3}\right], \mathrm{m}_{1}=1.89 \cdot 10^{6}\left[1 / \mathrm{m}^{2}\right]$, 

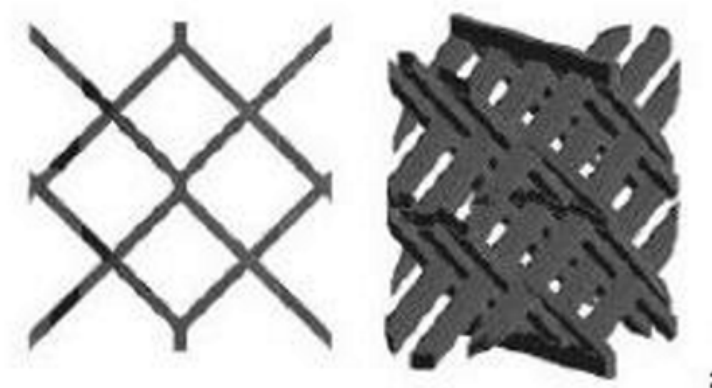

inlet

outlet

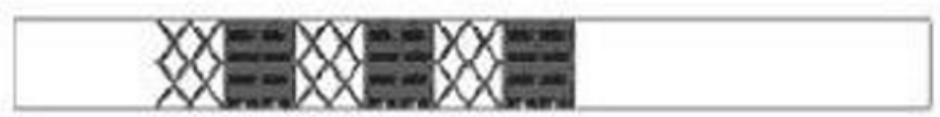

a
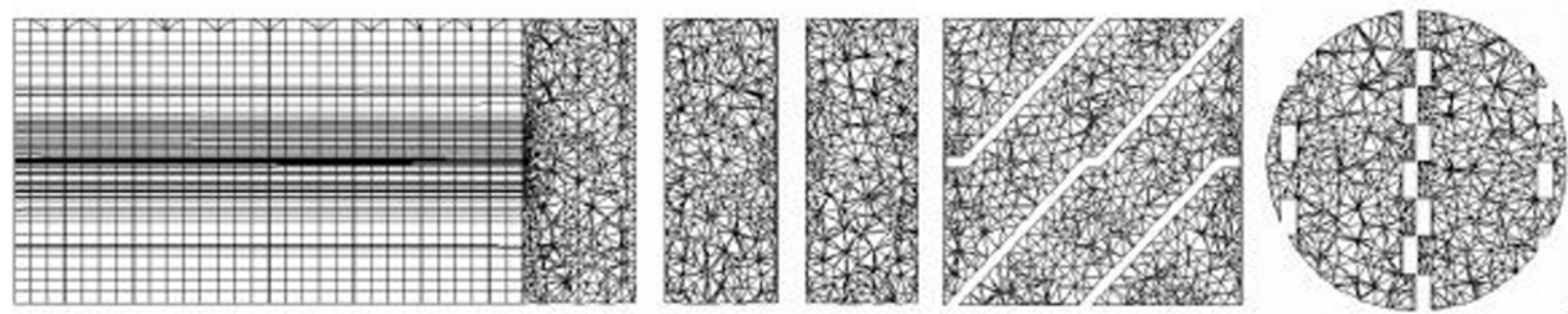

Figure 1. Geometry of the SMX insert (a), set of 6 SMX inserts inside the mixer tube (b), combined grid for a single insert $\operatorname{SMX}(854 \mathrm{k})(\mathrm{c})$

$\mathrm{m}_{2}=1900.3[1 / \mathrm{m}], \mathrm{m}_{3}=1.91[-], \mathrm{m}_{4}=1.92 \cdot 10^{-3}[\mathrm{~m}]$, $\mathrm{m}_{5}=1.93 \cdot 10^{-6}\left[\mathrm{~m}^{2}\right]$. The mean volumetric fraction of the dispersed phase was $1 \%$. The dispersed phase was introduced into the mixer through a coaxial tube of $1[\mathrm{~mm}]$ in diameter.

In order to quantify the effect of the centrifugal force on the phase concentration within the SMX mixer, three cases of different phase densities were simulated numerically for $\mathrm{Re}=10000$.

In the first, which mimicked the experimental conditions $^{31}$, the continuous phase density, $\rho_{c l}$, was equal to the density of water, $\rho_{H 2 O}=998.2\left[\mathrm{~kg} / \mathrm{m}^{3}\right]$, being higher than that for the dispersed phase, $\rho_{d 1}$, which was assumed as that for $\rho_{\text {oil }}=900\left[\mathrm{~kg} / \mathrm{m}^{3}\right]$. Thus, for the first case $\rho_{c 1}>\rho_{d 1}$.

In the second, fictitious case it was assumed that the two liquid phases have the same density, $\rho_{c 2}=\rho_{d 2}$ equal to that of water. In the third case, which was also virtual, the reverse density relation as in case 1 was assumed, i.e. $\rho_{c 3}=\rho_{d 3}$, with $\rho_{c 3}=\rho_{\text {oil }}$ and $\rho_{d 3}=\rho_{H 2 O}$. The viscosity values for the two phases were kept unchanged at the levels of $\mu_{c}=1.0 \cdot 10^{-3}$ [Pas] (as for water), $\mu_{d}=9.0 \cdot 10^{-4}$ [Pas] (as for oil), respectively for the continuous and dispersed phase. The interfacial tension was chosen as for the oilwater system at $0.0374[\mathrm{~N} / \mathrm{m}]$.

A prescribed velocity profile in the static mixer was used at the flow field inlet. During the computations, evolution of the hydrodynamic conditions was monitored for consecutive time steps at the three chosen positions within the region of the $5^{\text {th }}$ insert of the SMX static mixer. Local, instantaneous values of the axial component of the mixture velocity, $v_{z}$, the z-component of vorticity, $w_{z}$, and helicity value, $H_{e}$, were stored for further processing.

The second stage of the numerical analysis involved solutions of the transport equation set for the moments of the drop size distribution, eqn. (18). The number $\mathrm{K}$ value was chosen equal to 5 thus the local values of the first 6 moments were obtained from the simulations using 3 weights and 3 abscissas. Knowledge of the moment values suffices to reconstruct the drop size distribution.
The modelling was performed with the use of a numerical mesh generated in the specialized preprocessor Gambit 2.4.6 and a commercial CFD code, namely Fluent ${ }^{\mathrm{TM}}$ 6.3.26. An example of the combined (structured-unstructured) grid for the SMX mixer is shown in Fig. 1c. The grid comprises the inlet section consisting of the hexahedral elements and the remaining part, which was filled with triangular elements. The use of the structured part of the grid resulted in a decrease of numerical (false) diffusion in the inlet section ${ }^{30}$. The total number of grid cells was about 854 thousand, denoted here by $854 \mathrm{k}$. The momentum transfer iterations were performed with the default numerical parameters available in the code and the normalized residual sum of $10^{-6}$.

\section{RESULTS AND DISCUSSION}

The CFD modelling results for the pressure drop across one mixer insert show good agreement with the experimental data obtained by $\mathrm{Li}$ et $\mathrm{al}^{32}$. The friction factor values calculated from RANS and LES were equal to 1.12 and 0.925 , respectively, while Li et al. ${ }^{32}$ reported $\mathrm{f}=1.20$.

The mixing process in static mixers is mainly dominated by the axial flow, however the SMX insert strips make the fluid move also in perpendicular directions. The mean and instantaneous axial and radial velocities predicted by RANS and LES are shown in Figure 2.

Inspection of the velocity fields show similar distribution, however the k- $\varepsilon$ model predicts lower values and the contour plots are smoother. This suggests that RANS can give less accurate results than LES. Therefore, a closer analysis of fluid vorticity inside the mixer insert was undertaken since vorticity is a measure of the rotation of fluid element as it moves in the flow field. The comparisons of the z-direction local vorticity and the local mixture helicity in the SMX static mixer predicted by LES and RANS are shown in Figures 3 and 4. Instantaneous values of $\mathrm{z}$-direction vorticity and helicity achieved at three selected points in the mid-region of the $5^{\text {th }}$ insert $\left(L_{m}=H / 2\right)$ were recorded at the end of internal iterations 


\begin{tabular}{ccc}
\hline Parameter & RANS, $\mathrm{k}-\varepsilon$ model \\
\hline Axial velocity of \\
mixture, $\mathrm{v}_{\mathbf{z}}[\mathrm{m} / \mathrm{s}]$
\end{tabular}

Figure 2. Contour plots of the axial and radial mixture velocities in the middle cross section of the $5^{\text {th }}$ SMX insert (case 1 )
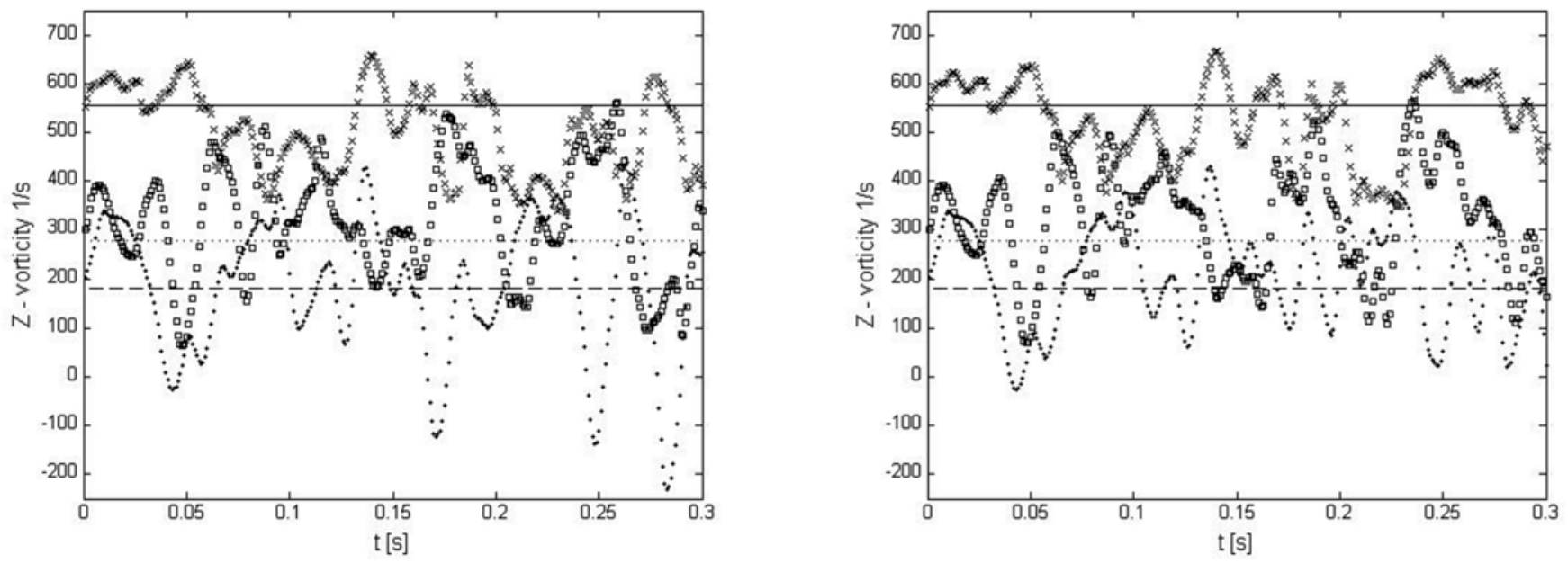

Figure 3. LES time history of the z-direction local vorticity in the SMX static mixer for case 1 (a) and case 2 (b) at the $R e=10000$, where: $x$ point $1, \mathrm{LES} ;+$ point 2 , LES; $\square$ point 3 , LES; — point 1 , RANS; point $2,--$ RANS; --.-. point 3, RANS

for each of the time steps at three selected points: $\mathrm{R}_{1}=0.009375[\mathrm{~m}]$ (point 1); $\mathrm{R}_{2}=0.00625$ [m] (point 2); $\mathrm{R}_{3}=0.003125[\mathrm{~m}]$ (point 3), located along the horizontal line.

The local z-direction vorticity RANS average for the two-phase mixture and for case 1 in the SMX static mixer were $556.2 ; 180.2$ and $278.5[1 / \mathrm{s}]$ for the three selected points, while from Fig.3(a) it can be seen how strongly the simulated local, instantaneous values of z-direction vorticity change from the local LES maximum of about $696.5[1 / \mathrm{s}]$ to the minimum close $-229.9[1 / \mathrm{s}]$. The local LES average values of the $\mathrm{z}$-direction vorticity for the selected points were around: 495.2; 166.0 and 294.8 [1/ s], i.e. close to those from RANS.

The simulated local helicity of the two-phase mixture also fluctuated strongly as shown in Fig.4. The local helicity RANS average for the two-phase mixture in the SMX static mixer for case 1 were $312.6 ; 60.9$ and $127.1\left[\mathrm{~m} / \mathrm{s}^{2}\right]$ at the three selected points. While for the same points the simulated local, instantaneous LES values of helicity change from the maximum of about $445.2\left[\mathrm{~m} / \mathrm{s}^{2}\right]$ to the minimum close $-61.7\left[\mathrm{~m} / \mathrm{s}^{2}\right]$ with the local LES average for the selected points of about $285.4 ; 51.9$ and $156.8\left[\mathrm{~m} / \mathrm{s}^{2}\right]$. Analysis of the plots in Figs. 3 to 5 reveals relatively high fluctuations in the local, instantaneous vorticity and helicity values predicted by LES. This allowed to conclude that such strong fluctuations of the flow can significantly influence the local centrifugal effects. However, the mean levels predicted by the LES technique have similar magnitude of vorticity and helicity to the corresponding mean levels predicted in the steady-state RANS mode.

The comparison of the COV values between the LES and experiments is shown in Figure 5. It follows that the LES results are lied intermediate between experimental 

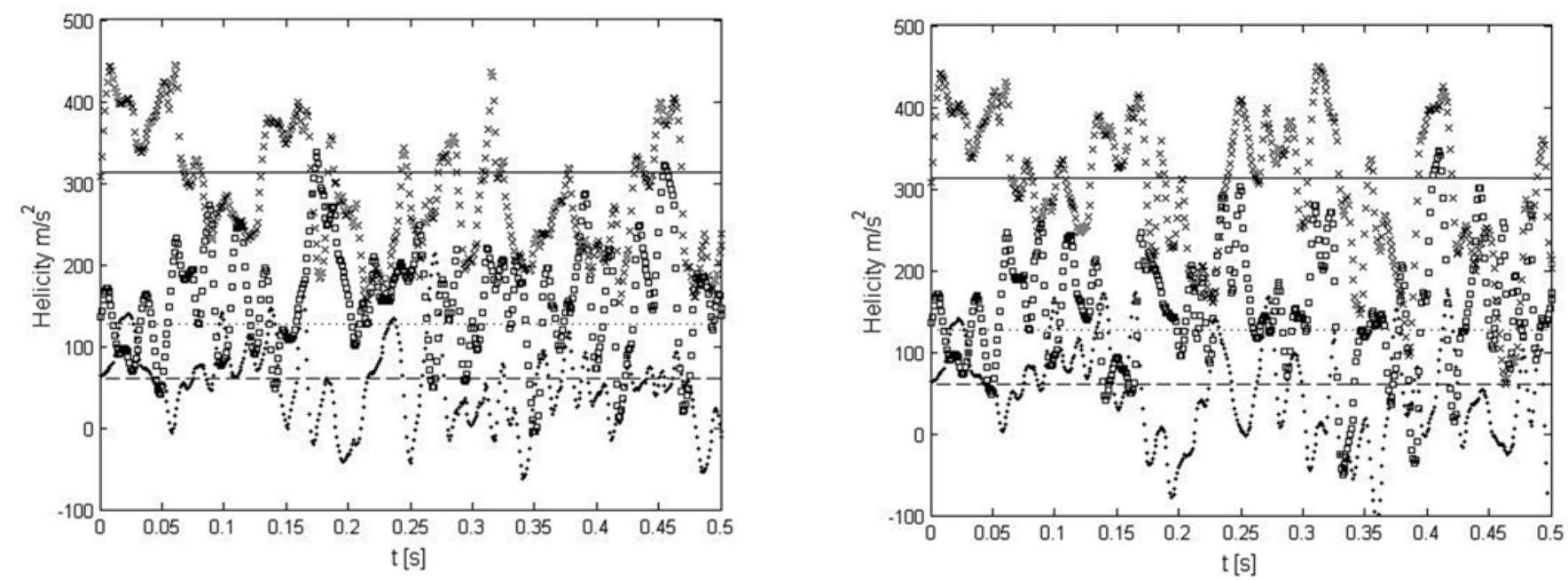

Figure 4. Evolution in time of simulated local mixture helicity in the SMX static mixer for case 1 (a), and case 2 (b) at the $R e=10000$, where: $x$ point 1 , LES; + point 2 , LES; $\square$ point 3 , LES; - point 1 , RANS; -- point 2 , RANS; --.-. point 3, RANS.

data for miscible liquids reported by different authors ${ }^{10,11,14,22}$. The homogeneity level obtained from LES simulations for cases 1 and 3 is characterized by almost constant value after the third SMX insert, while the experimental curves for the miscible mixtures exhibit a decreasing course.

The values of parameters $a$ and $b$ in functional form COV (eqn.3) were estimated from the numerical results and presented in Figure 5 and Table 1. The values of both coefficients obtained from RANS and LES methods are quite similar. These values differ a little bit from the values of coefficients $a$ and $b$ reported by Grosz-Roll ${ }^{12}$ and Cybulski and Werner ${ }^{13}$. However, Grosz-Roll ${ }^{12}$ and Cybulski and Werner ${ }^{13}$ carried out experiments for the SMX static mixer in laminar flow or for the SMV static mixer in turbulent flow ${ }^{\mathbf{1 2}}$, but they considered systems of the ratio $\mathrm{L}_{\mathrm{m}} / \mathrm{D}$ around 11 , while we considered $\mathrm{L}_{\mathrm{m}} / \mathrm{D}=14.3$. Still, values of coefficients $a$ and $b$ estimated from CFD results can be found between experimental data $^{12-13}$. As can be seen from Table 1 , the $R^{2}$ values for the exponential law profile for LES are generally above 0.84 and the values of the parameter $b$ for case 2 and both RANS and LES modes confirm the high rate of decrease in $C O V$ per unit of mixer length. It follows that the exponential law profile models are satisfactory for most mixing elements.

The differences of the COV values between the LES and RANS results can be compared from Figure 6 .

After the fourth insert the homogenisation level reached a satisfactory level for the case $2, \mathrm{COV}<0.05^{12}$, both for RANS and LES mode. For the case 1 and 3 the COV values obtained from the LES modelling are around 0.2 and 0.6 , respectively, which means that the dispersed phase is still not uniformly distributed across the SMX static mixer. The homogenisation level achieved in the RANS modelling for case 1 and 3 were higher than that obtained

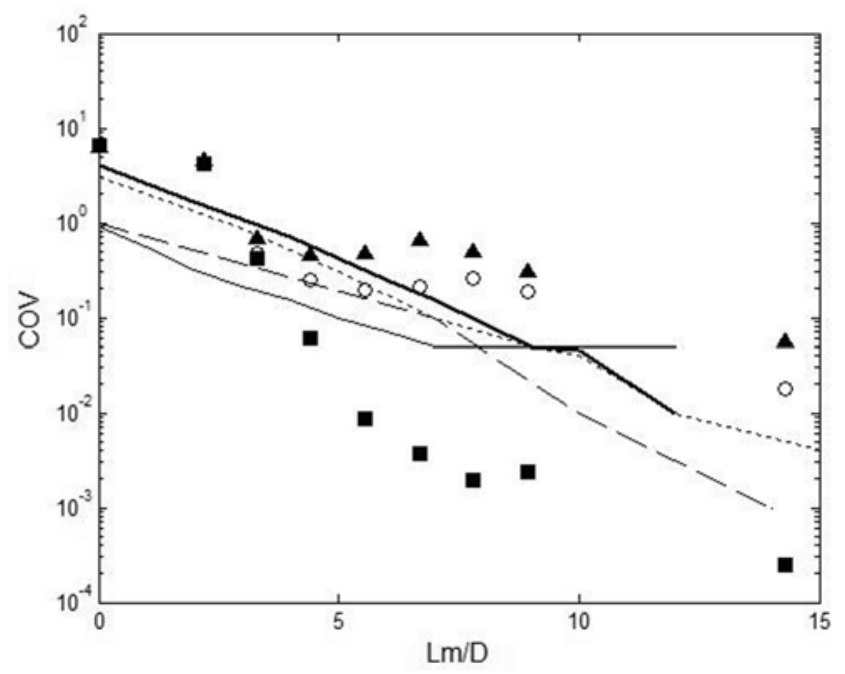

Figure 5. Concentration $C O V$ as a function of distance downstream from the inlet to the SMX static mixer at the $\mathrm{Re}=10000$ [-] for the LES and literature data, where: $O$ case 1 , LES; $\mathbf{\square}$ case 2, LES; $\boldsymbol{\Delta}$ case 3, LES; — Rauline et al. ${ }^{\mathbf{1 4}}$; — Pahl \& Muschelknautz ${ }^{10} ; . . .-$ Allocca $^{11} ;--$ Streiff et al. ${ }^{22}$

in the LES technique, which is a confirmation of lower phase segregation obtained in the transient LES simulations and lower effect of the centrifugal force.

The next stage of the numerical analysis involved solutions of the transport equation set for the moments of the drop size distribution, eqn. (18). During the simulation the local values of the first 6 moments $\left(m_{0}\right.$ to $\left.m_{5}\right)$ were obtained. The density distribution computed for the outlet of the SMX static mixer is graphically presented in Figure 7 . The size distribution is characterized by the Sauter mean diameter, $\mathrm{d}_{32}$, and the standard deviation, SD. The value of $d_{32}$ at the outlet from the SMX static

Table 1. The coefficients and adjusted- $\mathrm{R}^{2}$ for the exponential fits for the dispersed phase COVs

\begin{tabular}{|c|c|c|c|c|c|c|c|}
\hline \multirow{3}{*}{$\begin{array}{l}\operatorname{Re} \\
{[-]}\end{array}$} & \multirow{3}{*}{$\mathrm{L}_{m} / \mathrm{D}=14.3$} & \multicolumn{3}{|c|}{ RANS, k- $\varepsilon$} & \multicolumn{3}{|c|}{ LES } \\
\hline & & \multicolumn{2}{|c|}{$\mathrm{COV}=\mathrm{a} \cdot \exp \left(\mathrm{b}\left(\mathrm{L}_{\mathrm{m}} / \mathrm{D}\right)\right)$} & \multirow{2}{*}{$\begin{array}{c}\text { Adjusted } \\
\mathrm{R}^{2}\end{array}$} & \multicolumn{2}{|c|}{$\mathrm{COV}=\mathrm{a} \cdot \exp (\mathrm{b}(\mathrm{L} / \mathrm{D}))$} & \multirow{2}{*}{ Adjusted $\mathrm{R}^{2}$} \\
\hline & & $a$ & $\mathrm{~b}$ & & A & $\mathrm{b}$ & \\
\hline \multirow{3}{*}{ ㅇ } & case $1, \rho_{\mathrm{c} 1}>\rho_{\mathrm{d} 1}$ & 4.929 & -0.290 & 0.826 & 3.627 & -0.391 & 0.841 \\
\hline & case 2, $\rho_{\mathrm{c} 2}=\rho_{\mathrm{d} 2}$ & 4.039 & -0.782 & 0.815 & 3.645 & -0.813 & 0.869 \\
\hline & case $3, \rho_{\mathrm{c} 3}<\rho_{\mathrm{d} 3}$ & 5.745 & -0.348 & 0.897 & 4.162 & -0.314 & 0.847 \\
\hline
\end{tabular}




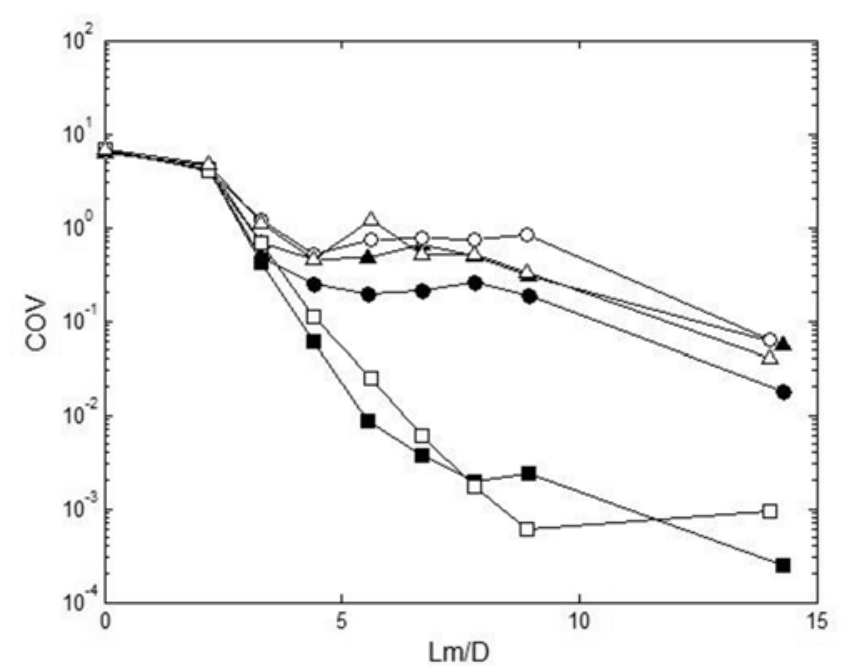

Figure 6. Concentration $C O V$ as a function of distance downstream from the inlet to the SMX static mixer for the LES and RANS $k-\varepsilon$ model simulations at $R e=10000$, where: $\rightarrow-$ case 1 , LES; $\rightarrow$ case 2 , LES; $\neg$ case 3 , LES; - - case 1 , RANS; $-\square-$ case 2 , RANS; $\triangle-$ case 3 , RANS

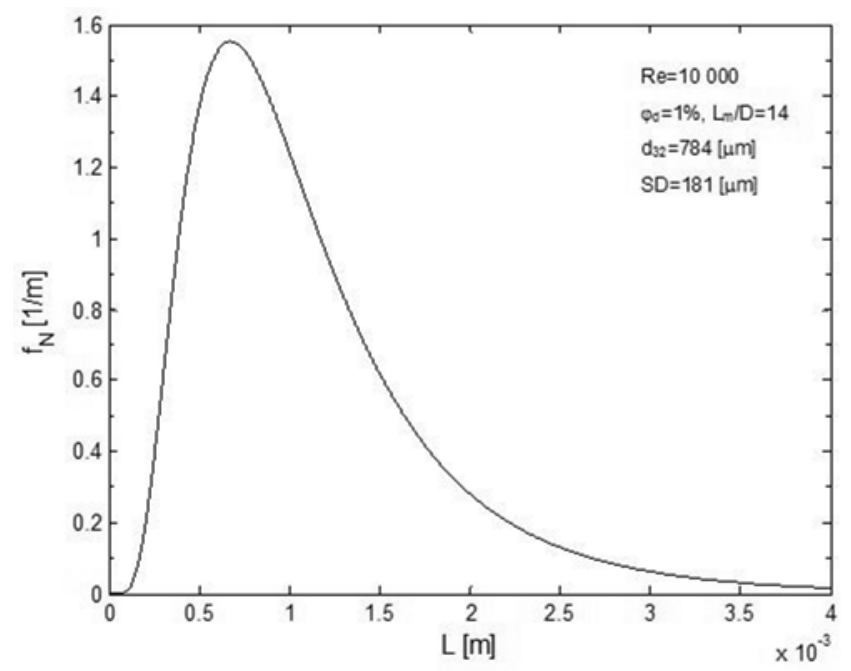

\section{CONCLUSIONS}

Numerical modelling using Eulerian-Eulerian approach to simulate liquid-liquid system under turbulent conditions coupled with a homogenous turbulence model in a steady-state (RANS) mode and Large Eddy Simulations in transient scheme were carried out. They resulted in predicting the flow field through a very complex geometry of the SMX static mixer. The pressure drop calculated from the RANS and LES agrees well with experimental results $^{32}$. The estimated $a$ and $b$ coefficients from the simulated concentration distributions were close to those from experiments ${ }^{12-13}$. In addition, local analysis of the break-up processes in two-phase flow was performed. Predicted mean drop diameter, $\mathrm{d}_{32}$, was accurately analysed using QMOM method and agrees well with experimental results?. The results obtained from the numerical modeling demonstrated that Computational Fluid Dynamics is a reliable method of modelling the SMX static mixer.

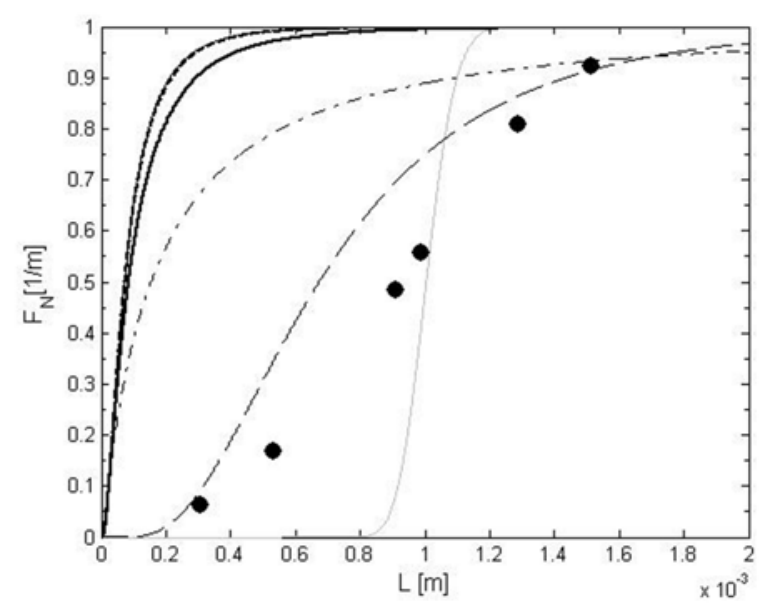

Figure 7. Drop density distribution for the outlet of the SMX static mixer (a) and cumulative drop size distribution functions for the chosen plane of the SMX static mixer at $\mathrm{Re}=10000$ for water-silicon oil system (b), where: $\mathrm{L}_{\mathrm{m}} / \mathrm{D}=0,-\cdots \mathrm{CFD}, \mathrm{L}_{\mathrm{m}} / \mathrm{D}=2.2,-\mathrm{CFD}, \mathrm{L}_{\mathrm{m}} / \mathrm{D}=3.3, \cdots \mathrm{CFD}, \mathrm{L}_{\mathrm{m}} / \mathrm{D}=5.6$, -

mixer was derived from the ratio of the third moment to the second moment, $\mathrm{m}^{3} / \mathrm{m}^{2}$.

Using the moment values, $\mathrm{m}_{\mathrm{k}}$, for the drop size distribution, two other distribution parameters were estimated, namely the skewness, $\mathrm{A}_{\mathrm{x}}$, and kurtosis, $\mathrm{A}_{\mathrm{y}}$. The values were close to $5.7 \cdot 10^{-4}$ and -2.99 for skewness and kurtosis, respectively. Thus the simulated distribution can be regarded as log-normal with a tendency to the right-side asymmetry. The cumulative drop distribution function computed for the outlet $\left(\mathrm{L}_{\mathrm{m}} / \mathrm{D}=14\right)$ of the SMX mixer was compared with the data obtained from equation (1) for drop size calculation estimated by Streiff et al. ${ }^{9}$. An example of that comparison is graphically presented in Figure 7(b). The shape of the reconstructed cumulative drop distribution curve (dashed line) was generally quite close to the experimental data?.

\section{Nomenclature}

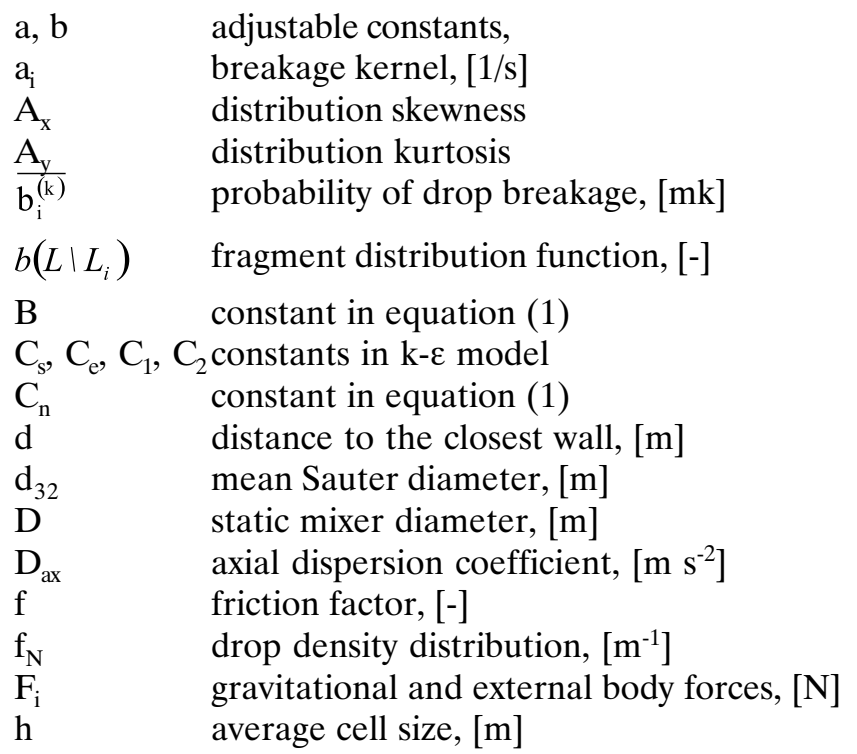


$\mathrm{k}$

K

$\frac{\mathrm{L}}{\mathrm{L}}$

L

$\mathrm{L}_{\mathrm{m}}$

$\mathrm{L}_{\mathrm{s}}$

$\mathrm{m}_{\mathrm{k}}$

$\mathrm{n}(\mathrm{L})$

$\mathrm{N}$

$\mathrm{p}$

$\mathrm{P}_{\mathrm{k}}, \mathrm{P}_{\varepsilon}$

$\mathrm{Pe}$

$\underline{\mathrm{Re}}$

$\overline{S_{i j}}$

$\mathrm{t}$

$\bar{v}$

$v_{D r d, i}$

V

$\mathrm{Vi}$

$\mathrm{w}_{\mathrm{i}}$

$\mathrm{We}_{\mathrm{c}}$

$\mathrm{x}, \mathrm{y}, \mathrm{z}$

$\mathrm{X}_{\mathrm{q}}$

$\bar{X}$

Greek symbols

$\delta_{\mathrm{ij}}$

$\varepsilon$

$\varphi_{d} \quad$ dispersed phase volume fraction, $\left[\mathrm{m}^{3} \mathrm{~m}^{-3}\right]$

$\kappa_{f} \quad$ wavenumber, $\left[\mathrm{m}^{-1}\right]$

$\lambda_{\mathrm{g}}$

$\mu_{q}$

$\mu_{T}$

$\rho_{\mathrm{q}}$

$\tau_{i j}$

$\sigma$

$\Gamma$

$\Gamma_{\mathrm{t}}$

\section{LITERATURE CITED}

1. Bottone, F. (2004). Investigation into the influence of solid concentration on solid-liquid mixing using PIV technique, Final year project thesis, University of Pisa, Italy.

2. Virdung, T. \& Rasmuson, A. (2003). PIV measurements of solid-liquid mixing at elevated concentrations, $11^{\text {th }}$ European Conference on Mixing, 3 - 5 October 2003 (pp.129 136). Bamberg, Germany.

3. Liu, S., Hrymak, N.A. \& Wood, P.E. (2005). Drop breakup in an SMX static mixer in laminar flow, Can. J Chem. Eng., 83, 793 - 807. DOI: 10.1002/cjce.5450830501.
4. Rama, Rao N.V., Baird, M.H.I., Hrymak, A.N. \& Wood, P.E. (2007). Dispersion of high-viscosity liquid-liquid systems by flow through SMX static mixer elements, Chem. Eng. Sci., 62, 6885 - 6896. DOI: 10.1016/j.ces.2007.08.070.

5. Fradette, L., Tanguy, P., Li, H.Z. \& Choplin, L. (2007). Liquid/liquid viscous dispersions with a SMX static mixer, Chem. Eng. Res. Des., 85 (A3), 395 - 405. DOI: 10.1205/ cherd06206.

6. Legrand, J., Morancais, P. \& Carnelle, G. (2001). Liquidliquid dispersion in an SMX-Sulzer static mixer, Chem. Eng. Res. Des, 79 (Part A), 949-956. DOI: 10.1205/ 02638760152721497.

7. Das, P.K., Legrand, J., Morancais, P. \& Carnelle, G. (2005). Drop breakage model in static mixers at low and intermediate Reynolds number, Chem. Eng. Sci., 60, 231 238. DOI: 10.1016/j.ces.2004.08.003.

8. Theron F., Le Sauze N. \& Ricard A. (2008). Emulsification using a SMX Sulzer static mixer in turbulent flow for a microencapsulation process, $6^{\text {th }}$ International Symposium on Mixing in Industrial Process Industries - ISMIP VI, 17 - 21 August 2008. Niagara Falls, Ontario, Canada.

9. Streiff, F.A., Mathys, P. \& Fischer, T.U. (1997). New Fundamentals for liquid-liquid dispersion using static mixers, Recents Progres en Genie des Procedes, 11(51), 307 - 314, ISBN 2-910239-25-X, editor Lavoisier, Paris, France.

10. Pahl, M.H. \& Muschelknautz, E. (1982). Static mixers and their applications. Int. Chem. Eng., 22, 2, 197 - 205.

11. Allocca, P.(1982). Mixing efficiency of static mixing units in laminar flow. Fib. Prod.,8, 12 - 19.

12. Grosz-Roll, F. (1980). Assessing homogeneity in motionless mixers, Int.Chem.Eng., 20, 542 - 549.

13. Cybulski, A. \& Werner, K. (1986). Static mixers - criteria for applications and selection, Int. Chem. Eng., 26(1), $171-180$.

14. Rauline, D., Le Blevec, J.M., Bousquet, J. \& Tanguy, P.A. (2000), A comparative assessment of the performance of the Kenics and SMX static mixers, Chemical Engineering Research and Design, 78 (Part A), 389 - 396. DOI: 10.1205/ 026387600527284.

15. Fradette, L., Li, H.Z., Choplin, L. \& Tanguy, P. (1998). 3D finite element simulation of fluids flow through a SMX static mixer, Comp. Chem. Eng., 22, S759-761, DOI: 10.1016/ S0098-1354(98)00142-2.

16. Hirschberg, S., Koubek, R., Moser, F. \& Schock, J. (2009). An improvement of the Sulzer SMX ${ }^{\mathrm{TM}}$ static mixer significantly reducing the pressure drop, Chem. Eng. Res. Des., DOI:10.1016/j.cherd.2008.12.021.

17. Visser, E.J., Rozendal, P.F., Hoogstraten, H.W. \& Beenackers, A.C.M. (1999). Three dimensional numerical simulation of flow and heat transfer in the Sulzer SMX static mixer, Chem. Eng. Sci., 54, 2491 - 2500. DOI: 10.1016/S00092509(98)00536-3.

18. Heniche, M., Tanguy, P.A., Reeder, M.F. \& Fasano, J.B. (2005). Numerical investigation of blade shape in static mixing, AIChE J, 51(1), 44 - 58. DOI: 10.1002/aic.10341.

19. Liu, S., Hrymark, A.N. \& Wood, P.E. (2006a), Design modifications to SMX static mixer for improving mixing, AIChE J, 52(1), 150 - 157. DOI: 10.1002/aic.10608.

20. Liu, S., Hrymak, A.N. \& Wood, P.E. (2006b). Laminar Mixing of Shear Thinning Fluids in a SMX Static Mixer. Chem. Eng. Sc., 61(6), 1753 - 1759. DOI:10.1016/ j.ces.2005.10.026.

21. Fourcade, E., Wadley, R., Hoefsloot, H.C.J., Green, A., \& Iedema, P.D. (2001). CFD calculation of laminar striation thinning in static mixer reactors. Chem. Eng. Sc., 56(23), 6729 - 6741. DOI: 10.1016/S0009-2509(01)00297-4.

22. Streiff, F.A., Jaffer, S. \& Schneider, G. (1999). The design and application of static mixer technology. $3^{\text {rd }}$ International Symposium on Mixing in Industrial Processes, 26 - 
27 September 1999, (pp.107 - 114), Osaka, Japan: European Federation of Chemical Engineering.

23. Lauder, B.E. \& Spalding, D.P. (1974). The numerical computation of turbulent flows, Comp. Meth. App. Mech. \& Eng., 3(2), 269 - 289. DOI: 10.1016/0045-7825(74)90029-2.

24. Wilcox, D.C. (1993). Turbulence Modelling for CFD, DCW Indus. Inc., California.

25. Sagaut, P. (2002). Large Eddy Simulation for Incompressible Flows, Springer-Verlag, Berlin.

26. Marchisio, D.L., Vigil, R.D. \& Fox, R.O. (2003). Quadrature method of moments for aggregation-breakage processes, J. Coll. Inter. Sci., 258, 322 - 334. DOI: 10.1016/ S0021-9797(02)00054-1.

27. McGraw, R. (1997). Description of aerosol dynamics by the quadrature method of moments, Aerosol Sci. Tech., 27, 2, 255 - 265. DOI: 10.1080/02786829708965471.

28. Gordon, R.(1968). Error bounds in equilibrium statistical mechanics, J. Math.Ph., 9(5), 655 - 672.

29. Randolph, A.D. \& Larson, M.A. (1988). Theory of particulate processes, Academic Press, San Diego.

30. Pianko-Oprych, P. \& Jaworski, Z. (2004). The numerical modelling of two-phase flows in static mixers, Inz. Chem. i Proc., 25, 341 - 362.

31. Pacek, A. \& Nienow, A. (1997). Breakage of oil drops in a Kenics mixer, Proc. Inten., $165-172$.

32. Li, H.Z., Fasol, C., \& Chopin, L. (1997). Pressure drop of Newtonian and non-Newtonian fluids across a Sulzer SMX static mixer. Chem. Eng. Res. Des., 75(8) 792 - 796. DOI: $10.1205 / 026387697524461$. 